\title{
Research on Intensity of Cooling Continuously Cast Steel by Water Nozzles
}

\author{
Marek Velička *, René Pyszko, Jiří Burda and Miroslav Příhoda \\ VŠB - Technical University of Ostrava, Faculty of Metallurgy and Materials Engineering, 17. listopadu 15, Ostrava - Poruba, 708 00, Czech Republic
}

\begin{abstract}
The article describes heat removal from the hot surface by water. Method of cooling in a secondary zone of continuous casting of steel has a significant influence on a quality of continuously cast products mainly from the point of view of internal and surface defects. For this reason, a physical model of the secondary zone has been developed at the Department of Thermal Engineering, which enables testing of both water and water-air nozzles. During laboratory modelling cooling effects of a nozzle have been expressed by means of two parameters. Most commonly used parameter is spray intensity, infrequently heat transfer coefficient is determined. In comparison with the cold model the energy and time consumption at measurements on the hot model are several fold higher. Therefore, also was found correlations between the two models.
\end{abstract}

Keywords: Heat transfer coefficient, cooling of surface, nozzle, continuous casting of steel.

\section{Introduction}

One of the most effective ways of heat removal, which is characterised by high values of the heat flux density, is cooling the hot surfaces by water or water-air nozzles. This method is used in numerous cooling processes both in laboratories and industry.

Considerable attention is paid at research working sites all over the world to the issues of cooling the hot surfaces. For example French researchers studied the single phase stationary cooling. The results showed the effect of the distance of the nozzle from the hot surface on emergence of film boiling [1]. In the American Wheaton Institute the so called variation coefficient is used for testing the intensity of spray nozzles admission, which characterises uniformity of overlapping spray patterns of individual nozzles in the system [2]. In Dayton thermal conditions during cooling of the hot surface are tested by the system of miniature nozzles using two types of coolant, namely water and methanol [3]. At the Oxford University, the influence of the flow of coolant at cooling of large hot surfaces on the distribution of cooling water drops was experimentally studied [4].

At the Clausthal University it was found by physical modelling that heat transfer coefficient at high temperatures in the area of film boiling of water is a function of the film boiling of water droplets [5]. Another possibility consists in the use of numerical models for simulation of heat transfer in acontinuous casting of steel. Indian researchers use for modelling of heat transfer in the secondary cooling area the dependence of heat transfer coefficient on the cooling water volume flow [6]. University of Helsinki [7] uses the method of 3D stationary modelling 
of temperature fields of solidifying continuously cast blanks. They use for calculation of the heat transfer coefficient in the secondary cooling area the knowledge of cooling water flow to the nozzle. The scientific team from the Technical University of Czestochowa [8] works on the development of two-dimensional numerical model, which calculates the heat removal from low carbon steels. A software based on the finite element method is used for determination of the temperature fields, thickness of strand shell and surface defects.

However, it flows from these literary sources, that the research works are limited only to specific types of nozzles. The obtained conclusions have therefore usually rather limited scope of validity. Another problem is also the existence of the Leidenfrost phenomenon, its dependence on the physical parameters and on the position of the cooled surface in respect to the nozzle axis. Particularly in the case of the nozzles with larger spray pattern, the local heat transfer conditions are not measured in detail. The difficulty of realisation of hot models of spraying leads to the search of dependencies between the heat transfer coefficient and the amount of cooling water, it means to analyse a correlation between the results of hot and cold spraying model.

\section{Physical Modelling}

Continuous casting of steel is exactly the technology, in which cooling of hot surface plays an important role. The quality of the continuously cast blank is to a large extent influenced by the manner of cooling by water or by water-air nozzles in the secondary area of the casting machine. Prevention of formation of surface defects and internal cracks requires certain cooling intensity and therefore possibilities increasing the efficiency of the existing heat removal systems are sought, allowing at the same time reduction of the cooling water consumption.

At the Department of Thermal Engineering of the VŠB - Technical University of Ostrava the secondary zone of blank cooling is assessed by the proprietary sophisticated cold and hot physical model. The cooling as such is evaluated not only from the perspective of uniform distribution of the cooling water and determination of spray characteristics, but also in terms of the distribution of heat transfer coefficient at individual points of the spray pattern.
An essential part of this research consists also in feedback verification of thus obtained heat transfer coefficients through numerical simulations.

The measured values of physical quantities are then used for assessment of the quality of newly used nozzles, for detection of possible structural defects, for comparison of nozzles from several manufacturers, for assessment of the degree of wear, and finally also as the boundary conditions for different numerical modelling of temperature fields of the cooled blank.

An objective comparison of the measured results on the physical models can only be performed when all input values are adhered to, such as are water pressure, distance of the nozzle from the measuring surface, cooling water temperature, and others [9].

\subsection{Spray characteristics of nozzles}

Cooling nozzles can be assessed by several characteristic indicators. The first one is linear spray characteristic, expressed by spray intensity according to the general equation:

$$
I=\frac{V}{S \cdot \tau} \quad\left(\mathrm{m}^{3} \cdot \mathrm{m}^{-2} \cdot \mathrm{s}^{-1}\right)
$$

where: $V$ is spray water volume $\left(\mathrm{m}^{3}\right), S$ - sprayed surface $\left(\mathrm{m}^{2}\right), \tau$ - time of spraying (s).

The first group of cold models has chambers in the shape of narrow parallel vertical slots when the nozzle and the chamber move in mutual respect to each other. The speed of displacement is optional and it corresponds to the speed of drawing of the blank on the real casting machine. The model of this structure is used for determination of the spray linear intensity, which integrates the quantity of water over the height of individual slots and provides information on the distribution of water across the width of the blank.

The second model (Figure 1), using an industrial robot, gives already full information about the two-dimensional distribution of water on the plane perpendicular to the nozzle axis at the given distance from the nozzle aperture, it means about the so called the spray areal intensity.

Calculation of areal intensity is performed according to the following equation:

$I=\frac{1}{\rho \cdot S_{a}} \cdot \frac{\Delta m_{i}}{\Delta \tau} \quad\left(\mathrm{m}^{3} \cdot \mathrm{m}^{-2} \cdot \mathrm{s}^{-1}\right)$ 
where: $\Delta \tau$ is time increment at individual steps of the scanning pattern (s), $\Delta m_{i}$ - water mass increment $(\mathrm{kg}), \rho$ - cooling water density $\left(\mathrm{kg} \cdot \mathrm{m}^{-3}\right)$, $S_{a}$ - surface of the collecting aperture $\left(\mathrm{m}^{2}\right)$.

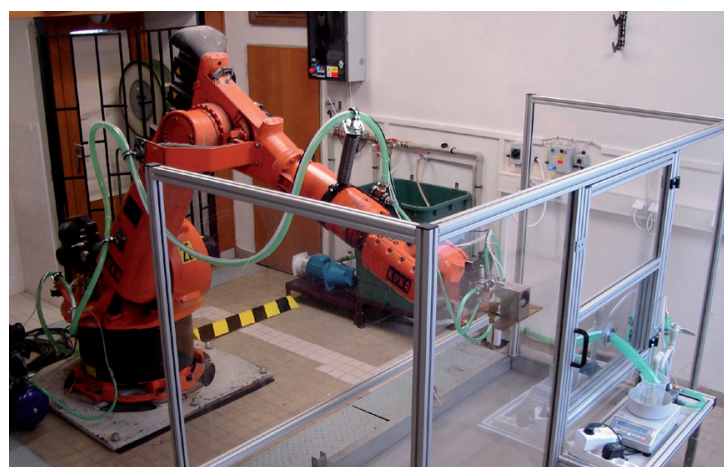

Fig. 1: Physical model for determination of the spray areal intensity.

For the experiment a test nozzle was selected at the pressure of $0.3 \mathrm{MPa}$ and the distance of $102 \mathrm{~mm}$ from the chamber slot, the resulting shape of the spray areal intensity is shown in Figure 2. The results of the measurements performed on this model confirmed the influence of the volumetric flow of cooling water on the value of spray areal intensity of given nozzles.

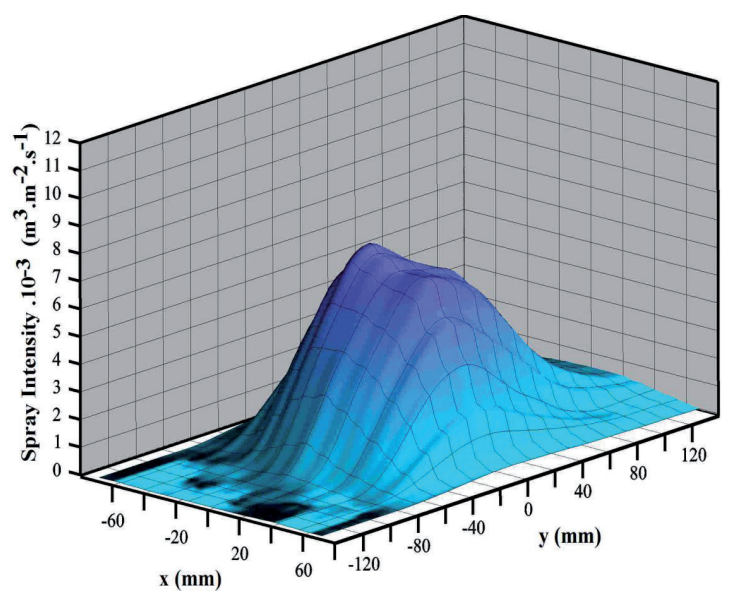

Fig. 2: Spray areal intensity.

On the basis of knowledge of the spray characteristics of individual types of nozzles it is also possible to determine a possible asymmetry of the spray, which is caused by wear and tear, by clogging or by a defect of the specific nozzle. Spray intensity distribution in majority of the tested spray nozzles corresponds approximately to the course of heat transfer coefficient measured on the hot model. This match, however, need not be valid for the whole range of pressures, cooling water flows and also for different temperatures of the cooled surface.

\subsection{Heat transfer coefficient}

Disagreement between the spray intensity at the secondary cooling zone and the heat flow removed from the cooled surface is related to the fact that heat removal from the blank is dependent, among others, on the size and speed of the water droplets, as well as on the temperature of the cooled surface. That is why it seems more advantageous to determination the intensity of cooling of hot surfaces with use of the heat transfer coefficient. However, determination of this quantity is rather difficult, because it is a function of the following variables:

$h=f\left(v, t_{1}, t_{2}, \lambda, c_{p}, \rho, \eta, l, \theta\right)\left(\mathrm{W} \cdot \mathrm{m}^{-2} \cdot \mathrm{K}^{-1}\right)$

where: $v$ is rate of the fluid flow $\left(\mathrm{m} \cdot \mathrm{s}^{-1}\right), t_{1}, t_{2}$ temperature of the fluid and of the cooled surface $\left({ }^{\circ} \mathrm{C}\right), \boldsymbol{\lambda}$ - thermal conductivity coefficient of the fluid $\left(\mathrm{W} \cdot \mathrm{m}^{-1} \cdot \mathrm{K}^{-1}\right), \mathrm{cp}-\quad$ specific heat capacity $\left(\mathrm{J} \cdot \mathrm{kg}^{-1} \cdot \mathrm{K}^{-1}\right), \eta$ - dynamic viscosity of the fluid (Pa.s), $l$ - dimensions of the body (m), $\theta$ - body shape coefficient (1).

For this reason various experimental methods for measurement of the values of heat transfer coefficient $h$ at the temperatures corresponding to the operating conditions of the particular casting machine are being developed.

In the Institute of Japan [10] an equation was derived for calculation of the heat transfer coefficient in the secondary zone during spraying as a function of volumetric flow rate and temperature of cooling water in the form:

$h=\frac{2,25 \cdot 10^{4} \cdot W^{0,55} \cdot\left(1-0,0075 \cdot T_{\mathrm{w}}\right)}{\psi}\left(\mathrm{W} \cdot \mathrm{m}^{-2} \cdot \mathrm{K}^{-1}\right)$

where: $W$ is the density of cooling water $\left(. \mathrm{cm}^{-2}\right.$. $\left.\mathrm{min}^{-1}\right), T_{\mathrm{w}}$ - thermodynamic temperature of cooling water $(K), \psi$ - the angle between the surface of the blank and the horizontal plane (rad).

Another of the used methods works on the principle of induction or flame heated measuring plate of larger dimensions [11]. After heating the plate to the appropriate temperature, the heating is stopped and the plate is exposed to the cooling effect of the tested nozzle. Temperatures of the 
plate are measured by thermocouples. Calculation of the heat transfer coefficient is performed in such cases by the inverse method, where the heat flux is calculated, from which the coefficient $h$ is then determined. The main problem of the models of this design construction is the need of precise determination of the physical properties (thermal conductivity coefficient and temperature conductivity coefficient) of the material used for the testing plate in the entire temperature range.

The method for determination of the heat transfer coefficient, used at the department of thermal engineering [12], eliminates these deficiencies and it is based on the principle of measurement the electric input needed for maintaining a constant temperature on the heated measuring facet of the probe. Position of the probe is fixed, the cooling nozzle moves in front of the probe in two perpendicular coordinates $x, y$. The limit values of $x$ and $y$ coordinates are determined by the desired pattern of the cooled surface. The distance from the probe centre from the plane of movement of the nozzle is constant (Figure 3).

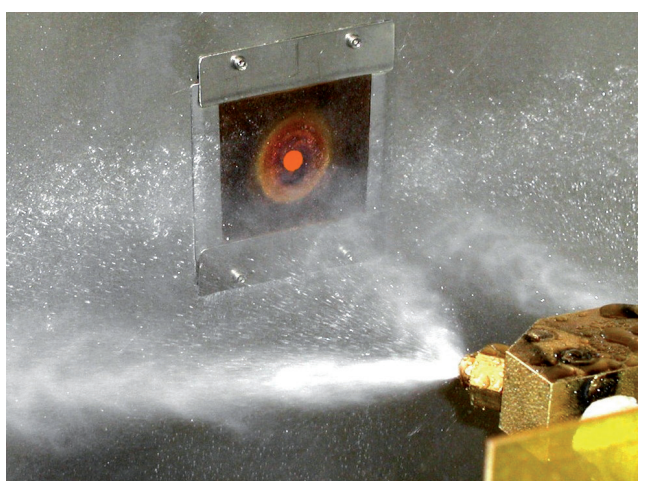

Fig. 3: Directly heated probe of the physical model.

Values of the local heat transfer coefficient on the nozzle spray pattern then form a matrix with the elements $h_{i, j}$. For different cooling water pressures and probe temperatures it is thus possible to obtain the functional dependence of the local and overall intensity of cooling on the cooling water pressure or on the temperature of the cooled surface.

Value of the coefficient $h$ at the point of measurement is determined from the relation:

$h_{i, j}=\frac{P_{\mathrm{ok}}-P_{\mathrm{z}}}{S_{\mathrm{s}} \cdot\left(t_{\mathrm{s}}-t_{\mathrm{w}}\right)} \quad\left(\mathrm{W} \cdot \mathrm{m}^{-2} \cdot \mathrm{K}^{-1}\right)$ where: $i$ is index in the direction of the coordinate $x$; $i=\langle 1, n\rangle, j$ - index in the direction of the coordinate $y ; j=\langle 1, m\rangle, P_{\mathrm{ok}}$ - instant input into the probe $i, j$ $(\mathrm{W}), P_{\mathrm{z}}$ - loss heat flow $(\mathrm{W}), S_{\mathrm{s}}$ - probe surface $\left(\mathrm{m}^{2}\right)$, $t_{\mathrm{s}}$ - probe temperature $\left({ }^{\circ} \mathrm{C}\right)$.

The advantages of the probe include the fact that basic quantities needed for determination of the removed heat flow are electrical quantities, the measurement of which is relatively simple and accurate. The working part of the probe is heated by electric resistance and electric input is measured, which ensures a constant temperature of the probe. Electrical input supplied onto the measuring surface, equals the heat flow removed from this part of the probe. After deducting the losses the measured input is then used for calculation of the coefficient $h$. The losses are determined by calibration of the probe at the beginning and the end of each measurement.

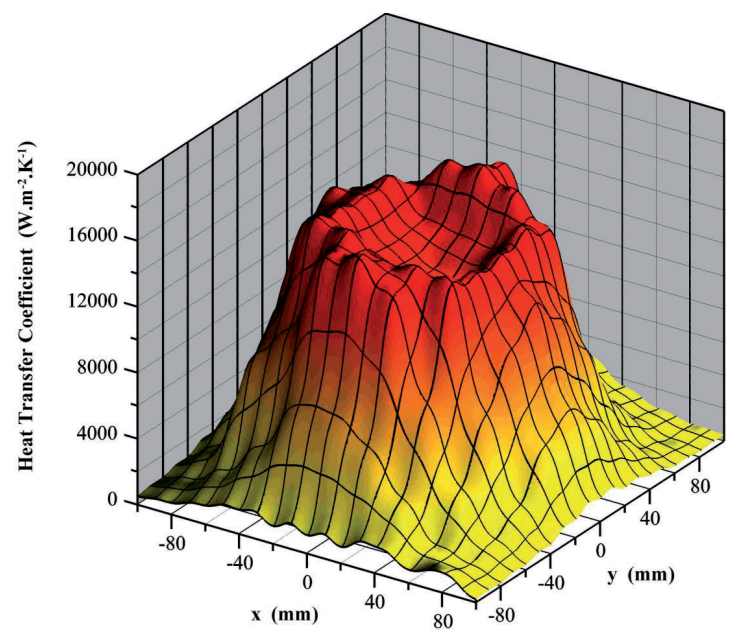

Fig. 4: Heat transfer coefficient.

Figure 4 shows the areal distribution of the heat transfer coefficient during spraying in dependence on the spray pattern coordinate of the test nozzle for the temperature of $600^{\circ} \mathrm{C}$. For the test measurement a scanning step of $20 \mathrm{~mm}$ was used and total overall dimension of the sprayed surface was $200 \mathrm{~mm} \times 200$ $\mathrm{mm}$, and the measurement parameters were the same as for measurement of the spray intensity.

It should be mentioned that directly heated probe did not prove good at testing of the nozzles with a cooling water flow rate exceeding $10 \mathrm{l} \cdot \mathrm{min}^{-1}$. During intensive heating of the probe the heat losses to the surroundings beyond the actively cooled 
surface increased. The impossibility of accurate measurement of these losses then resulted in larger errors at calculation of the heat transfer coefficient. For this reason, at the department of thermal engineering a hot physical model with indirectly heated probe, working in non-stationary mode, was also built.

\section{Discussion}

The above described methods can be used not only for determination of the boundary conditions as such, but they also enable replacement, on the basis of the determined dependencies, of the more energy consuming and time consuming measurements of the heat transfer coefficient by a simpler method for determination of the spray linear intensity.

The general dependence of heat transfer coefficient in the secondary cooling zone in the case of the cold physical model is given by the functional dependence:

$$
h=f(I) \quad\left(\mathrm{W} \cdot \mathrm{m}^{-2} \cdot \mathrm{K}^{-1}\right)
$$

Finding of given dependencies is not simple from the viewpoint of heat removal at cooling of hot surfaces, because the heat transfer coefficient depends not only on the distance and on the amount of cooling water, but also on the size and kinetic energy of water droplets. Generally speaking, the droplet size and velocity gives the intensity of heat removal. In the case of perfect atomisation a water mist is formed, which due to the high temperature of the cooling surface evaporates earlier, than in the case of large droplets, where a risk of formation of undesirable film boiling exists, which reduces the intensity of heat removal. On the basis of knowledge the droplet kinetic energy it is possible to determine under certain simplifying assumptions the amount of water, which is reflected away from the surface. This fact is related to the hot surface temperature, since at higher surface temperatures almost a complete evaporation of all sizes of droplets takes places.

Measurements on physical models significantly differ from each other. While at the measurement of spray characteristics, only the pressure of the cooling water and the distance from the nozzle are considered as variables, at the measurement of the heat transfer coefficient it is necessary to consider also the temperature of the cooled surface. This temperature considerably influences the value size of the heat removal from the surface of the solidifying blank.

On the basis of hundreds of laboratory measurements of nozzles it was determined by correlation analysis that the dependence of heat transfer coefficient on the spray intensity is approaching the power function:

$$
\frac{h}{h_{\text {ref }}}=\left(\frac{I}{I_{\text {ref }}}\right)^{n}
$$

where: $h$ is heat transfer coefficient $\left(\mathrm{W} \cdot \mathrm{m}^{-2} \cdot \mathrm{K}^{-1}\right), h_{\text {ref }}$ - reference value of the heat transfer coefficient $\left(\mathrm{W} \cdot \mathrm{m}^{-2} \cdot \mathrm{K}^{-1}\right), I$ - spray intensity $\left(\mathrm{m}^{3} \cdot \mathrm{m}^{-2} \cdot \mathrm{s}^{-1}\right), I_{\text {ref }}$ reference value of spray intensity $\left(\mathrm{m}^{3} \cdot \mathrm{m}^{-2} \cdot \mathrm{s}^{-1}\right), n$ exponent (1).

In the event that the spray intensity is used in the relation, the reference value of the spray intensity is given by the mean element of the slot chamber, and the reference value of heat transfer coefficient is measured in the centre of the scanning pattern of the tested nozzle.

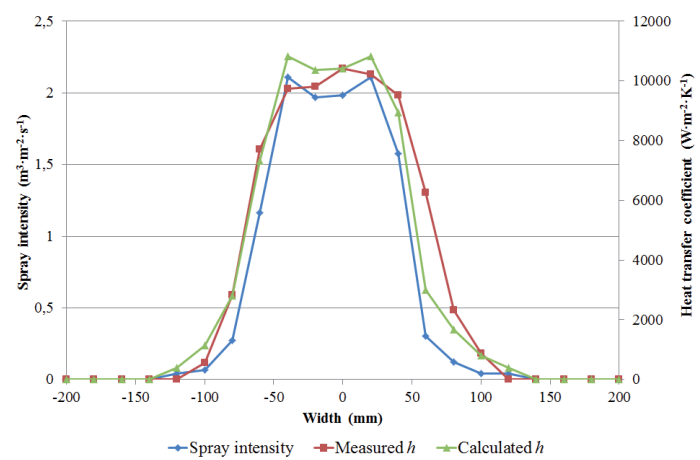

Fig. 5: Spray intensity, measured and calculated value $h$.

Figure 5 shows the measured average values of the coefficient $h$ in the centre of the spray pattern, together with the calculated values of heat transfer coefficient calculated by the statistical method of least squares and also measured values of spray linear intensity.

It follows from the performed test measurements, that the degree of correlation between the spray intensity and heat transfer coefficient considerably differs for different sizes of nozzles and for other operating parameters used on the real casting machine. 
For smaller nozzles significantly better agreement was observed between the measured and calculated values of heat transfer coefficient both for higher and lower temperatures of the cooled surface. For larger nozzles the degree of correlation partly differs, which might have been be caused by a certain portion of water, which, due to the higher flow rate, is reflected from the surface.

\section{Conclusion}

Heat removal from the hot surface by water spray is a complex physical phenomenon. It is difficult to define mathematically the entire cooling process that is why physical modelling is mainly used for solution. In the laboratories of physical modelling the conditions of heat transport from the surface of solid bodies during the cooling by water nozzles are examined.

In comparison with the cold model the energy and time consumption at measurements on the hot model are several fold higher. An effort therefore exists to find correlations between both models. It follows from the obtained experiments that the observed dependencies are approaching the power function and for determination of the exponent $n$ a statistical method of least squares was used. For calculation of the average values of the coefficient $h$ it is therefore necessary to know only the spray intensity and the reference value of the coefficient $h$, measured at the centre of the spray pattern.

These obtained dependencies can be used as boundary conditions for simulation models addressing kinetics of the blank temperature field as it passes through the casting machine.

\section{Acknowledgments}

This paper was elaborated in frame of tasks related to the soIution of the project SP2015/86 and SP2015/70-FMMI VŠB TUO.

\section{References and Notes}

[1] ROBIDOU, H., AURACHER, H., GARDIN, P., LEBOUCHÉ, M. Controlled cooling of a hot plate. In 5th Conference on Experimental Heat Transfer, Fluid Mechanics and Thermodynamics, 24.-28. 9. 2001. Thessaloniki, Greece.

[2] HAGERS, J. J. Basic Technical considerations for application of spray nozzles to chemical processing. 47th Chemical Processing Industry Exposition. New York: 1997.

[3] LIN, L., PONNAPPAN, R. Heat transfer characteristics of spray cooling in a closed loop. International Journal of Heat and Mass Transfer. 2003, 46(20), 3737-3746. ISSN 0017-9310.
[4] VORSTER, W. J. J., SCHWINDT, S. A., SCHUPP, J., KORSUNSKY, A. M. Analysis of the spray field development on a vertical surface during water spray-quenching using a flat spray nozzle. Applied Thermal Engineering. 2009, 29(7), 14061416. ISSN 1359-4311.

[5] WENDELSTORF, J., SPITZER, K. H., WENDELSTORF, R. Spray water cooling heat transfer at high temperatures and liquid mass fluxes. International Journal of Heat and Mass Transfer. 2008, 51(19-20) 4902-4910. ISSN 0017-9310.

[6] SHAMSI, M. R. R. I., AJMANI, S. K. Analysis of mould, spray and radiation zones of continuous billet caster by three-dimensional mathematical model based on a turbulent fluid flow. Steel Research International, 2010, 81 (2), 132-141. ISSN 1611-3683.

[7] LOUHENKILPI, S., MÄKINEN, M., VAPALAHTI, S., RÄISÄNEN, T. LAINE, J. 3D steady state and transient simulation tools for heat transfer and solidification in continuous casting. Materials Science and Engineering: A. 2005, 413-414, 135-138. ISSN 0921-5093.

[8] JANIK, M., DYJA, H., BERSKI, S., BANASZEK, G. Two-dimensional thermomechanical analysis of continuous casting process. Journal of Materials Processing Technology. 2004, 153-154, 578-582. ISSN 0924-0136.

[9] ČARNOGURSKÁ, M., PŘíHODA, M., HAJKR, Z., PYSZKO, R., TOMAN, Z. Thermal effects of a high-pressure spray descaling process. Materiali in Tehnologije $=$ Materials and Technology. 2014, 48(3), 389-394. ISSN 1580-2949.

[10] NOZAKI, J., MATSUNO, K., MURATA, H. et al. A secondary cooling pattern for preventing surface cracks of continuous casting slab. Transactions of the Iron and Steel Institute of Japan. 1978, 18(6), 330-338. ISSN 1881-1183 (online), 00211583 (print).

[11] RAUDENSKÝ, M., HORSKÝ, J. Secondary cooling in continuous casting and Leidenfrost temperature effects. Ironmaking and Steelmaking. 2005, 32(2), 159-164. ISSN 0301-9233 (print) 1743-2812 (online). DOI 10.1179/174328105×15913.

[12] PŘíHODA, M. et al. Heat Transfer during Cooling of Hot Surfaces by Water Nozzles. Metalurgija = Metallurgy. 2009, 48(4), 235-238. ISSN 0543-5846.

\section{Biographical notes}

Marek Velička, Ing., Ph.D., graduated at the Faculty of Metallurgy and Materials Engineering of VŠB - Technical University of Ostrava. He works as assistent professor of the Department of Thermal Engineering of VŠB - Technical University of Ostrava. His research is focused on modelling of thermal processes and statistical methods for processing and analysis of data, using numerical models for research of thermal processes and temperature fields in technological processes. From all of his significant publications there are 5 scientific articles published in Web of knowledge database, 5 scientific articles published in Scopus database and many other research publications. 
René Pyszko, doc. Dr. Ing., graduated at the Faculty of Mechanical Engineering of Technical University in Brno. He works as a deputy head of the Department of Thermal Engineering of VŠB - Technical University of Ostrava. His research is focused on physical and mathematical modeling of thermal processes, on-line monitoring and simulation of the continuous casting process, technical measuring and data processing. From all of his significant publications there are 12 scientific articles published in Web of knowledge database, 11 scientific articles published in Scopus database and many other research publications.

Jiři Burda, Ing., graduated at the Faculty of Electrical Engineering and Computer Science of VǏB - Technical University of Ostrava. He works as assistent professor of the Department of Thermal Engineering of VŠB - Technical University of Ostrava. His research is focused on Measurement of thermophysical properties of metallic materials and thermal regulation equipment, experimental measurement and evaluation of measured data, especially in continuous casting of steel. From all of his significant publications there are 3 scientific articles published in Web of knowledge database, 3 scientific articles published in Scopus database and many other research publications.

Miroslav Přihoda, prof. Ing., CSc., he is a graduate of Faculty of Metallurgy at Mining University in Ostrava. Currently works at the Department of Thermal Engineering at Faculty of Metallurgy and Materials Engineering, VŠB - Technical University of Ostrava and is a authority for heat processes within industrial and municipal sphere. His research is concentrated on mathematical and physical modeling of thermal processes, thermal work of basic units of continuous casting equipment, temperature conditions in metal recuperators, utilization of steel enthalpy at metallurgical plants, determination of thermal conductivity and thermal diffusivity at high temperatures. From all of his significant publications there are 16 scientific articles published in Web of knowledge database, 36 scientific articles published in Scopus database and many other research publications. 